\title{
Purification and characterization of membrane-bound polyphenoloxidase (mPPO) from Snake fruit [Salacca zalacca (Gaertn.) Voss].
}

\begin{abstract}
Membrane-bound polyphenoloxidase (mPPO) an oxidative enzyme which is responsible for the undesirable browning reaction in Snake fruit (Salacca zalacca (Gaertn.) Voss) was investigated. The enzyme was extracted using a non-ionic detergent (Triton X-114), followed by temperature-induced phase partitioning technique which resulted in two separate layers (detergent-poor phase at the upper layer and detergent-rich phase at the lower layer). The upper detergent-poor phase extract was subsequently fractionated by $40-80 \%$ ammonium sulfate and chromatographed on HiTrap Phenyl Sepharose and Superdex 200 HR 10/30. The $\mathrm{mPPO}$ was purified to 14.1 folds with a recovery of $12.35 \%$. A single prominent protein band appeared on native-PAGE and SDS-PAGE implying that the $\mathrm{mPPO}$ is a monomeric protein with estimated molecular weight of $38 \mathrm{kDa}$. Characterization study showed that $\mathrm{mPPO}$ from Snake fruit was optimally active at $\mathrm{pH} 6.5$, temperature $30^{\circ} \mathrm{C}$ and active towards diphenols as substrates. The $\mathrm{Km}$ and Vmax values were calculated to be $5.46 \mathrm{mM}$ and $0.98 \mathrm{U} / \mathrm{ml} / \mathrm{min}$, respectively, when catechol was used as substrate. Among the chemical inhibitors tested, 1cysteine showed the best inhibitory effect, with an IC50 of $1.3 \pm 0.002 \mathrm{mM}$ followed by ascorbic acid $(1.5 \pm 0.06 \mathrm{mM})$, glutathione $(1.5 \pm 0.07 \mathrm{mM})$, EDTA $(100 \pm 0.02 \mathrm{mM})$ and citric acid $(186 \pm 0.16 \mathrm{mM})$.
\end{abstract}

Keyword: Snake fruit (Salacca zalacca); Membrane-bound polyphenoloxidase; Extraction; Purification; Characterization. 